Int. J. Electrochem. Sci., 15 (2020) 4619 - 4630

International Journal of

ELECTROCHEMICAL

SCIENCE

WWW.electrochemsci.org

\title{
Fabrication of novel electrochemical sensor based on MXene/MWCNTs composite for sensitive detection of synephrine
}

\author{
Meng $\mathrm{Gao}^{1}, \mathrm{Yu} \mathrm{Xie}^{2}$, Wuliang Yang ${ }^{1, *}$, Limin $\mathrm{Lu}^{2, *}$ \\ ${ }^{1}$ Key Laboratory of Modern Preparation of TCM of Ministry of Education, College of Traditional \\ Chinese Medicine, Jiangxi University of Traditional Chinese Medicine, Nanchang 330045, PR China \\ ${ }^{2}$ Key Laboratory of Crop Physiology, Ecology and Genetic Breeding, Ministry of Education, College \\ of Science, Jiangxi Agricultural University, Nanchang 330045, PR China \\ *E-mail: jxutcm_zyx@126.com, lulimin816@hotmail.com
}

doi: $10.20964 / 2020.05 .79$

Received: 29 December 2019 / Accepted: 21 February 2020 / Published: 10 April 2020

In this study, the composite of MXene/multi-wall carbon nanotube (MXene/MWCNTs) was prepared and utilized to construct electrochemical sensor for detecting synephrine. The MXene/MWCNTs material has both the advantages of MXene and MWCNTs, including large electrochemically active surface, good physical and chemical properties of MXene, and high electrical conductivity as well as excellent electrocatalytic activity of MWCNTs. These excellent properties ensure high sensitivity. In addition, the structure of the material was characterized by scanning electron microscope (SEM) and X-ray diffraction (XRD). The application of the modified electrode was studied by cyclic voltammetry (CV) and linear sweep voltammetry (LSV). Under optimized experimental conditions, a linear relationship between the peak current and the concentration of synephrine was established in the range of $0.5 \sim 70 \mu \mathrm{M}$. A low limit of detection of $0.167 \mu \mathrm{M}$ was obtained. The modified electrode also showed good repeatability, stability and anti-interference ability.

Keywords: MXene; MWCNTs; Electrochemical sensor; Synephrine.

\section{FULL TEXT}

(C) 2020 The Authors. Published by ESG (www.electrochemsci.org). This article is an open access article distributed under the terms and conditions of the Creative Commons Attribution license (http://creativecommons.org/licenses/by/4.0/). 